\title{
LE GOUT DÉFECTUEUX (GOUT HUILEUX-RANCI, SUIFFEUX ET AMER) DU LAIT
}

\section{Dr JOSEF PROK $\breve{S}$}

Professeur

(Ecole supérieure agricole de Brno,

Tchécoslova quie). par

\author{
JAROMîR GROH \\ Ingénieur agronome \\ (Section lactologique de l'Institut \\ zootechnique de Moravie
}

à Brno).

Le goût "huileux-ranci " du lait est un défaut désagréable qui peut déprécier beaucoup le lait. Il se présentait autrefois sporadiquement et n'est apparu de manière importante que dans les dernières années, surtout en Autriche, en Hongrie et en Allemagne. A la fin de l'année 1933 et au eommencement de 1934, il s'est généralisé d'une façon remarquable également dans certaines contrées de la Moravie et il y causa de grands dommages. Ce goût " huileuxranci " est ordinairement accompagné d'un arrière-goût amer et souvent suiffeux. Dans la littérature allemande, ce défaut est introduit sous le nom de "schmirgelige " ou "ölig-talgige Milch". La littérature concernant ce défaut est, dès aujourd'hui, assez considérable. Ses indications sont d'accord pour dire que ce mauvais goût du lait survient, en règle générale, pendant les mois d'hiver et que, dans des troupeaux à gros effectif, le lait de toutes les vaches n'est pas atteint, mais seulement celui de quelques-unes.

Les avis, sur le fond et la cause de ce défaut, diffèrent beaucoup. D'après les résultats des travaux actuels, il ne s'agit probablement pas d'un seul défaut, mais des défauts différents qui provoquent des altérations bien semblables de goût du lait, mais différentes par leur origine. Ainsi, par exemple, A. St AfFe [1] a constaté que le lait au goût rude se rencontre pendant l'alimentation aux tourteaux et aux têtes de betterave. Après la traite, le lait était normal, plus tard, surtout pendant la conservation au froid, il a présenté un goût d'abord douceâtre, puis rude, avec un arrière-goût souvent métallique et presque toujours ranci. Du lait défeetueux, il a isolé le Bacillus Welchii, à l'aide duquel il a été possible de provoquer le même défaut dans le lait tiède. Mais on n'a pas pourtant pour cela donné la cause exacte du lait au goût "rude-ranci ", survenant en masse. Un an plus tôt que STAFFE, Rudolf [2] indique aussi à l'origine du défaut, les microorganismes du groupe Bacterium aerogenes. Il a analysé des laits défectueux et a constaté que leur composition chimique n'était pas anormale. A l'encontre de ces recherches, il y en a d'autres qui n'indiquent pas les microorganismes comme étant à l'origine du défaut constaté. Ainsi, DinRNHOFER [3] explique l'altération du goût du lait par la dégradation 
de l'acide oléique de la matière grasse en matières volatiles solubles dans l'eau. Cette dégradation dépend de la présence de certains catalyseurs. Les recherches de l'auteur montrent que la cause du défaut constaté ne sont pas les microorganismes. La connexion entre le défaut et le fourrage est établi par les recherches de MAJER [4] et de Winkler [5]. Majer constatait le défaut dans les étables, où l'on utilisait intensément les résidus de sucrerie. Le remplacement des résidus par le foin redonnait un goût normal au lait. De même, WINKLER a constaté que ce défaut survenait au cours des mois d'hiver, pendant l'alimentation aux tourteaux et aux têtes de betterave et en même temps que l'on donnait aux animaux des rations faibles ou pas du tout de foin.

KENDE [6] étudiait soigneusement le goût "huileux-ranci » au " huileux-suiffeux " du lait. Il remarquait que le lait de certaines grandes fermes à l'exploitation intensive, moins souvent celui des petites fermes, montrait pendant les mois d'hiver un goût défectueux. Après la traite, le lait avait un goût normal; mais 24-48 heures après, il prenait un goût huileux-ranci. Il impute l'origine de ce défaut à une enzyme jusqu'alors inconnue, qu'il a nommée l'oléinase. Cette dernière existe dans le lait en qualité de proenzyme et elle est mise en activité par suite de contact avec certains métaux lourds. KENDE attribue la possibilité de l'oxydation de la matière grasse du lait et de l'origine du goût « huileux-suiffeux " aux facteurs suivants : $1^{0}$ à la composition de la matière grasse du lait - plus elle contient d'acides gras non saturés, plus l'oxydation est facile; $2^{\circ}$ à la présence de l'oléinase, mais l'activité de celle-ci dépend de la présence des métaux lourds, qui peuvent, dans certaines circonstances, causer l'altération, eux-mêmes. Contre l'oxydation agissent les substances réductrices : réductases du lait ou réductases bactériennes.

La connexion entre le goût défectueux du lait et les métaux lourds est prouvée par WEICH et BAUER [7] qui ont eonstaté le goût "huileux-suiffeux" du lait, infecté par des particules de cuivre provenant d'une vieille pompe. En même temps le lait venait du régime alimentaire d'été, et, d'autre part, même $40 \mathrm{~kg}$. de têtes de betterave ensilées par jour ne pouvaient pas provoquer le défaut dans le lait. Les auteurs en concluent que l'origine du goût défectueux n'est pas lié à la nature du fourrage. Le travail de Prokš [8] prouve que l'origine du goût huileux-ranci peut dépendre de la composition de la matière grasse du lait; l'auteur a trouvé dans un lait au goût ranci très prononcé une matière grasse très riche en acide oléique. Le goût ranci du lait est expliqué aussi par ses propriétés lipolytiques. Ce furent Palmer [9], puis GrRber et HäNe [10], mais surtout KösTLER, ROADHOUSE et LöRTSCHER [11] qui montrèrent 
la relation fréquente entre la gravidité avancée des vaches ou l'état anormal des organes génitaux et la sécrétion d'un lait qui, bientôt après la traite, prenait, sous l'influence des enzymes lipolytiques, un fort goût ranci. Kös'cLER a nommé un tel lait "lipolytique-actif " (lipolytisch aktive Milch). De même Csiszár [12] attribue l'origine du goût huileux-ranci du lait à l'action dégradante d'une lipase spéciale du lait sur la matière grasse du lait. Il a trouvé aussi chez un grand nombre de vaches au lait défectueux, ou bien la gravidité avancée ou bien quelques écarts de la fonction sexuelle. Il admet la possibilité de la participation de quelques microorganismes pendant le développement de l'altération. Mais il ne pouvait, dans aucun cas, attribuer l'origine de celle-ci à l'influence du fourrage. En résumé, on peut alors indiquer comme cause du goût " hủileux-ranci ", éventuellement "huileux-suiffeux " ou "amerastringent " du lait, d'après les recherches actuelles, ou les microorganismes, ou l'enzyme d'oxydation (oléinase), ou enfin l'enzyme lipolytique. Quelquefois, peut également contribuer à une rapide altération du goût de la matière grasse, sa composition anormale. Dans tous les cas cités il est probable que, en général, il ne s'agissait pas du même défaut, mais de plusieurs défauts, se ressemblant quant aux altérations du goût provoquées.

\section{RECHEROHES PERSONNELLES}

Dans l'étable de l'Institut zootechnique de Brno, il s'est trouvé trois vaches donnant un lait au goût défectueux, bien pareil aux défauts cités plus haut. De même, à la ferme modèle de Žabèice, appartenant à l'Ecole supérieure agricole de Brno, un tel défaut du lait a été constaté naturellement chez un petit nombre de vaches; parmi les 116 vaches examinées, six seulement donnaient un lait au fort goût ranci, huileux et quelquefois amer.

Au moment des recherches, la vache $n^{0} 238$ était à trois mois, la vache $n^{\circ} 135$ à six mois, $n^{\circ} 254$ à deux mois, $n^{\circ} 231$ à cinq mois, $n^{\circ} 262$ à deux mois, $n^{\circ} 190$ à sept semaines avant le vêlage. Comme on le voit, à l'exception de la vache $\mathrm{n}^{\circ} 135$, toutes les autres étaient en gestation avancée. Les vaches de l'étable expérimentale de l'Institut zootechnique étaient, au commencement de la recherche, aux stades de lactation suivants : $n^{\circ}$ VI, neuf mois après le vêlage ; $\mathrm{n}^{0} \mathrm{X}$, au septième mois de la gravidité (un mois après survint l'avortement, le fotus était de huit mois); $n^{0}$ XI, sept mois après le vêlage. Egalement, dans ces trois cas, on pouvait parler de lactation avancée. Pour permettre une meilleure possibilité de contrôle constant et une manipulation plus facile avec le lait, on n'a soumis à une recherche attentive que le lait des trois vaches de l'étable de l'Institut zootechnique de Brno. 
Le commencement de la recherche data du 16 février 1934. Au début de la recherche, les vaches ont reçu les rations suivantes (par bête et par jour) : $15 \mathrm{~kg}$. de betterave, $5 \mathrm{~kg}$. de pommes de terre, $0 \mathrm{~kg}$. 5 de pulpes de sucrerie, $3 \mathrm{~kg}$. de foin de luzerne, $2 \mathrm{~kg}$. de foin, $1 \mathrm{~kg}$. de paille hachée, $1 / 4$ de kilo de tourteaux de soja et $1 / 2$ kilo de tourteaux d'arachide, $3 / 4$ de kilo de son de froment, $0 \mathrm{~kg}$. 5 de germes. Du 20 février au 8 mai jusqu'à l'époque du fourrage vert, la ration a été changée ainsi : $4 \mathrm{~kg}$. 5 de pulpes-drèches, $3 \mathrm{~kg}$. de foin de luzerne, $2 \mathrm{~kg}$. de foin, $1 \mathrm{~kg}$. de paille hachée, $0 \mathrm{~kg}$. 25 de tourteaux de lin, $0 \mathrm{~kg}$. 5 de son de froment, $0 \mathrm{~kg}$. 5 de germes. Comme on le voit, la ration était composée de telle manière qu'elle donnait la possibilité d'obtenir un lait sans défauts.

Le lait des trois vaches était, au cours des recherches, toujours goûté aussitôt après la traite ; dans tous ces cas, le goût et l'odeur ne montraient pas aussitôt après la traite de qualités frappantes. Le défaut apparaissait toujours après un temps plus long et sa naissance fut étudiée dans plusieurs recherches ci-décrites, Le lait était goûté en même temps par 2 à 4 personnes.

Pendant la première recherche, les laits des trois vaches ont été partagés en deux lots : l'un a été laissé cru, l'autre a été cuit. Les deux ont été conservés en froid et, après un certain temps, ont été soumis à la recherche : 24 heures après, les laits cuits ont été sans changement, quant au goût et à l'odeur. Il en était autrement pour les laits crus. Les laits particuliers des trois vaches montraient les qualités suivantes :

Vache no VI : un faible arrière-goût métallique.

Vache $n^{\circ} \mathrm{X}$ : goût métallique, fort, ranci et amer.

Vache $\mathbf{n}^{\circ}$ XI : goût fort, ranci.

36 heures après, les laits cuits ont été encore sans changement, tandis que les laits crus, conservés en froid, montraient les qualités suivantes :

No VI : un arrière-goût suiffeux, très faible.

$N^{\circ} \mathrm{X}$ : goût fort, ranci, amer.

No XI : goût huileux, ranci, amer.

Pendant cette recherche, on a pratiqué aussi une recherche bactériologique des laits. Mais on n'a pas réussi à cultiver, à partir de ces laits, les microorganismes capables de provoquer, dans le lait, le défaut de goût ci-dessus décrit. Pour cette raison, les recherches bactériologiques n'ont pas été continuées.

Pour pouvoir constater l'influence des métaux, et éventuellement celle de la différence de température pendant la conservation, on a fait une étude spéciale au cours de laquelle le lait a été trait dans des 
vases de verre. On a exclu tout contact avec le métal. Le lait a été partagé en cinq lots. Deux échantillons ont été pris dans des vases de verre : l'un a été conservé au froid, à une température de +4 à $+11^{\circ} \mathrm{C}$., l'autre à la température de la chambre, environ $+18^{\circ} \mathrm{C}$. Deux autres échantillons ont été, afin de se trouver en contact avec le métal, versés après la traite dans des seaux étamés, et passés au tamis à lait en métal. Puis, ils ont été de nouveau versés dans les vases de verre; l'un a été conservé au froid (à une température de $+4 \grave{a}+11^{\circ}$ C.), l'autre à la température de la chambre. Le dèrnier échantillon a été versé dans un seau à traire en métal étamé, et conservé à une température de $+10^{\circ} 5$ à $+13^{\circ} \mathrm{C}$.; le lait était ainsi en contact prolongé avec le métal. La constatation des qualités du lait a été faite 24-48 heures après la traite. Les échantillons ont été désignés de la manière suivante :

№ 1 : le lait sans contact avec le métal, conservé au froid.

№ 2 : le lait sans contact avec le métal, conservé à la température de la chambre.

№ 3 : le lait au contact du métal, conservé au froid.

No 4 : le lait au contact du métal conservé à la température de la chambre.

No 5 : le lait au contact prolongé du métal, conservé au froid.

Les recherches ont donné les résultats suivants :

Vache $n^{\circ} \nabla \boldsymbol{f}$.

Echantillon $n^{0} 1 \ldots$

Echantillon $n^{\circ} 2 \ldots$

Echantillon n ${ }^{\circ} 3 \ldots$

Echantillon $n^{\circ} 4$..

Echantillon $n^{0} 5$..

Vache $n^{0} X$.

Echantillon $\mathbf{n}^{\circ} 1$..

Echantillon $n^{\circ} 2 \ldots$

Echantillon $n^{\circ} 3$..

Echantillon $n^{\circ} 4$..

Echantillon $n^{\circ} 5 \ldots$
Goût

24 heures après

normal

normal

normal

normal

faiblement huileux-ranci et amer

ranci, huileux, fortem ${ }^{t}$ amer ranci-suiffeux, amer (moins fortem ${ }^{t}$ que l'éch. $n^{0} 1$ )

huileux, ranci, forte $\mathrm{m}^{\mathrm{t}}$ amer suiffeux, faiblement ranci, très faiblement amer

fortement ranci, amer
48 heures après

normal

normal

normal

un peu aigre

faiblement huileux-ranci $\mathrm{\epsilon t}$ amer

huileux-ranci, forte $m^{t}$ amer huileux-ranci, suiffeux, plus faiblement amer

huileux-ranci, amer

ranci, amer (plus faiblement que l'échant. $n^{\circ} 3$ )

très fortement ranci, suiffeux, amer 
Vache $n^{\circ} X I$ 24 heures après

Echantillon no 1 .. très faiblement ranci

Echantillon $n^{\circ} 2 \ldots$

Echantillon $n^{0} 3$.. huileux, ranci, fortem ${ }^{t} a m e r$

Echantillon $n^{\circ} 4$.. ranci, faiblement amer

Eichantillon $n^{\circ} 5$.. assez fortem ${ }^{t}$ huileưix-ranci, amer
Goût

48 heures après

faiblement ranci, suiffeux, amer

huileux-ranci, a mer

huileux-ranci, amer

huileux-ranei, amer

huileux-ranci et fortement amer

On voit que le contact du lait avec le métal avait pour conséquence la formation du défaut constaté à un degré plus élevé. Pour le lait no VI, les échantillons qui n'étaient pas en contact prolongé avec le métal, étaient en général sans défaut. Pour les laits $\mathrm{n}^{\circ} \mathrm{X}$ et $\mathrm{XI}$, tous les échantillons étaient d'un goût défectueux. La température plus basse pendant la conservation du lait avait pour effet un goût défectueux plus fort. La conservation du lait à la température de la chambre avait presque toujours pour conséquence un degré moindre du défaut. Il faut ajouter que tous les échantillons au goût huileux-ranci ou suiffeux se distinguaient par une odeur de caractère analogue.

Parallèlement, on a fait une étude en effectuant la pasteurisation des laits fraîchement traits des vaches $\mathrm{n}^{\text {os }} \mathrm{VI}, \mathrm{X}$ et XI. On a réalisé des chauffages atteignant jusqu'à $90^{\circ}$ C. pendant 5 minutes ; $80^{\circ} \mathrm{C}$. pendant 5 minutes ; $63^{\circ} \mathrm{C}$. pendant 30 minutes.

Tous les laits pasteurisés avaient, même après une conservation de trois jours au froid, un goût normal.

Les recherches suivantes ont été faites dans le but de constater quel élément du lait était à la base de l'apparition de l'altération. Dans ce but, on a écrémé le lait des vaches particulières, fraîchement traites. Ici, il faut de nouveau souligner qu'aussitôt après la traite, on ne pouvait constater dans aucun lait, quelque altération du goût. De même, après l'écrémage, ne pouvait-on ni dans la crème ni dans les laits écrémés constater de goût spécial. Seule eonstatation, la couleur de tous les échantillons de crème montrait une nuance un peu rosée.

La teneur en matière grasse des laits écrémés était la suivante :

\begin{tabular}{|c|c|}
\hline Lait de la vache $n^{\circ}$ VI & 0,03 \\
\hline Lait de la vache $n^{0} X$. & 0,11 \\
\hline Lait de la vache $n^{\circ}$ XI & 0,05 \\
\hline
\end{tabular}

Une partie des laits traits a été laissée telle que, à cause du contrôle. La crème obtenue de chaque vache a été toujours partagée en deux parties. Une partie a été barattée, l'autre a été conservée 
pour les épreuves du goûter. La crème était très difficile à baratter et n'a donné du beurre que le deuxième jour.

Le lait écrémé a été partagé en 5 échantillons, dont l'un a été conservé à l'état cru; le deuxième a été cuit; les autres ont été soumis à la pasteurisation aux températures suivantes : $90^{\circ} \mathrm{C}$. pendant 5 minutes; $80^{\circ} \mathrm{C}$. pendant 5 minutes ; $63^{\circ} \mathrm{C}$. pendant 30 minutes.

Les épreuves par goûter ont été faites 24,48 et 72 heures après ; et, en attendant, tous les échantillons étaient conservés en froid. Les laits entiers, crus, ont montré le goût défectueux dès le deuxième jour. Pendant cela, le lait de la vache no VI avait une mauvaise odeur huileuse et un goût huileux très faible; ce même goût huileux faible a été trouvé aussi dans le lait $n^{\circ} \mathrm{XI}$, tandis que le lait $n^{\circ} \mathrm{X}$ avait une mauvaise odeur de rance et le goût amer-huileux et ranci.

Les babeurres, obtenus après le barattage d'une partie de la crème, présentaient les caractères suivants : celui de la crème $n^{\circ}$ VI n'avait aucun défaut de goût, ceux venant des crèmes $X$ et XI étaient huileux-rancis et amers, avec une mauvaise odeur huileuse-rancie.

Les beurres obtenus montraient les qualités suivantes :

Beurre VI : 24 heures après, le goût était sans défaut ; ce n'était que trois jours après, qu'il était possible de constater un petit arrière-goût suiffeux, à peine perceptible.

Beurre $X$ : Déjà après 24 heures, le goût a été huileux-suiffeux, ranci et amer, mais, même après 3 jours, il n'était pas aussi accentué que celui constaté dans le lait dont le beurre était issu.

Beurre $X I: 24$ heures après, goût faiblement suiffeux, très peu amer, rude, qui même après 3 jours n'était pas trop accentué.

Des beurres examinés on a préparé la matière grasse pure et on a mesuré le degré de réfraction à l'aide du réfractomètre de Zeiss. On a obtenu à $40^{\circ} \mathrm{C}$., les indices suivants :

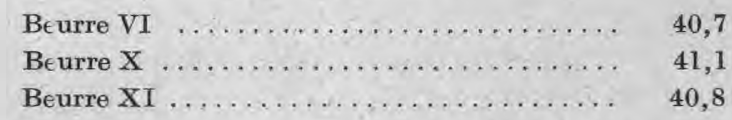

Les indices trouvés pour la réfraction ont été, pour tous les beurres, tout à fait normaux et mutuellement très proches. Donc, les laits des vaches examinées ne contiennent pas de matières grasses d'une composition anormale.

Les crèmes ont montré, à l'examen, les qualités suivantes :

Crème VI : le défaut ne se montrait pas, même après trois jours.

Crème $\mathrm{X}$ : était déjà, après 24 heures, huileuse-rancie et amère.

Crème XI : était déjà, après 24 heures, huileuse-rancie et amère. 
Trois jours après, on a fabriqué, à partir des crèmes examinées, du beurre qui montra les qualités suivantes:

Beurre VI : goût et odeur très bons.

Beurre $\mathrm{X}$ : goût faiblement suiffeux-ranci, amer; le défaut est plus faible que dans la crème originelle.

Beurre $\mathrm{Xi}_{\mathrm{i}}$ : goût ranci, fortement amer.

Le babeurre était chez le $n^{\circ}$ VI d'un goût normal, chez le $n^{\circ} \mathrm{X}$ très amer et huileux, chez le $\mathrm{n}^{\circ} \mathrm{XI}$ huileux-ranci, fortement amer. Les défauts de goût étaient, dans le babeurre, plus accentués que dans le beurre.

Les laits écrémés des trois vaches, à partir du moment où ils ont été euits ou pasteurisés, sont restés sans changement; le défaut ne s'est pas montré, ce à quoi on pouvait s'attendre. Quant aux laits écrémés crus : le lait no VI n'était pas, même après trois jours, d'un goût défectueux; le lait $\mathrm{n}^{\circ} \mathrm{X}$ était, déjà le deuxième jour, un peu huileux et très peu amer; le lait $n^{\circ}$ XI montrait, seulement après trois jours, un très faible arrière goût amer. Ilfaut préciser que, dans le lait écrémé $n^{\circ}$ VI, on a trouvé la moindre, et, dans le lait $n^{\circ} \mathrm{X}$, la plus grande quantité de matière grasse.

On peut conclure que le taux de matière grasse est en relation avec le goût défectueux du lait. Mais, en même temps, il est frappant de constater que la dispersion de la matière grasse dans le plasma du lait est favorable à la naissance du défaut. La matière qui produit le changement de la matière grasse, est probablement contenue dans le plasma du lait. Les substances " de goût " qui se produisent par suite de la décomposition de la matière grasse, sont probablement solubles dans l'eau, parce que les "qualités de goût» de la crème défectueuse se sont montrées plutôt dans le babeurre que dans le beurre, fabriqué à partir de cette crème.

A la question posée : le plasma du lait contient-il le facteur causant l'altération de la matière grasse et, en conséquence, le goût défectueux du lait?, la recherche suivante devait répondre :

Le lait de la vache no XI a été partagé en 3 parties. Une partie a été conservée au froid. L'autre partie a été écrémée et la crème comme le lait écrémé ont été partagés en deux lots : un lot a été conservé cru, l'autre a été pasteurisé. La troisième partie du lait entier originel a été pasteurisée et conservée au froid. Puis, on a mélangé la crème crue avec le lait écrémé pasteurisé, dans la proportion de 1:4, puis, la crème pasteurisée avec le lait écrémé cru en même proportion; les mélanges ont été conservés au froid. Une partie de la crème crue et de la crème pasteurisée, de même qu'une partie du lait écrémé cru et aussi du lait écrémé pasteurisé ont été conservées non mélangées, à cause du contrôle. Tous les échantillons 
ont été, pendant quelques jours de suite, goûtés. Les résultats ont été les suivants :

Le lait originel cru : huileux-ranci, amer.

Le lait originel pasteurisé : sans défaut.

La crème crue : huileuse, fortement rancie, amère.

La crème pasteurisée : sans défaut.

Le lait écrémé cru : sans défaut.

Le lait écrémé pasteurisé : sans défaut.

La crème crue + le lait pasteurisé : sans défaut.

La crème pasteurisée + le lait écrémé cru : le goût fortement ranci.

La recherche a été répétée avec la crème et le lait écrémé de la vache $n^{\circ}$ XI et de celle $n^{\circ} 238$ de la ferme modèle de Žabčice, appartenant à l'Ecole supérieure agricole de Brno; les résultats ont été les mêmes. La recherche avec la crème et le lait écrémé de la vache n० 238 a été répétée trois fois (les 4, 7 et 14 mai). En même temps on a soumis à l'étude également, la matière grasse du lait de cette vache et on a trouvé :

$\begin{array}{lccc}\text { L'indice d'iode } \ldots \ldots \ldots \ldots \ldots \ldots & \text { le } 4 \text { mai } & \text { le } 7 \text { mai } & \text { le } 14 \text { mai } \\ \text { L'indice de réfraction à }+40^{\circ} \mathrm{C} . & 35,66 & 36,49 & 39,71 \\ & 42,6 & 42,9 & 43,9\end{array}$

La matière grasse du lait se distinguait par un degré de réfraction et un indice d'iode assez élevés, surtout celle du 14 mai (régime alimentaire d'été), mais les indices trouvés sont encore normaux.

Les recherches faites prouvent que le facteur modifiant la matière grasse est contenu sûrement dans le plasma du lait. C'est une matière vivante qui perd par la pasteurisation son activité, done une enzyme, et, d'après son effet, une enzyme lipolytique.

Puis, on a fait des recherches semblables en préparant divers mélanges des laits entiers. Par exemple, on a mélangé le lait cru $n^{\circ}$ VI avec le lait cru $n^{\circ} X$, dans la proportion de $100 / 1,50 / 1,60 / 3$. Une simple addition de $3 \mathrm{~cm}^{3}$ du lait $\mathrm{n}^{\circ} \mathrm{X}$ à $60 \mathrm{~cm}^{3}$ du lait $\mathrm{n}^{0}$ VI avait pour conséquence un goût fortement huileux, tandis que pour le lait pur no VI, aussi bien que pour les autres mélanges, le goût était seulement un peu huileux. Il en était de même pour les mélanges du lait VI et XI. Le lait $n^{\circ} \mathrm{X}$ non mélangé était fortement ranci, huileux, amer; le lait no XI un peu ranci, fortement huileux.

Ces recherches corroborent les résultats des recherches précédentes, à savoir que l'enzyme, contenue dans le plasma du lait, est cause de l'altération de la matière grasse. Sa quantité est proportionnelle à la quantité du plasma et, pour cette raison aussi, le lait $n^{\circ} \mathbf{X}$, conservé seul, montre le défaut très prononcé, et, ajouté en 
petite quantité au lait $n^{\circ}$ VI, il n'augmente que légèrement son goût défectueux.

Les recherches suivantes devaient montrer comment agit le lait des quartiers individuels de la mamelle. Pour cela, on a trait les vaches $n^{\circ} \mathrm{X}$ et $\mathrm{XI}$ de telle manière que le lait de chaque quartier fût recueilli séparément. Pendant les premières heures après la traite, aucun lait n'a présenté de défaut. Pendant la première recherche concernant ce groupe, ce n'était que 5 heures après la traite qu'on pouvait constater un goût très peu huileux sur les laits des deux quartiers postérieurs de la vache $n^{\circ} \mathrm{X}$. Le lait des quartiers antérieurs ne montrait pas encore d'altération. Le lait de la vache $n^{0}$ XI ne montrait pendant ce temps rien de particulier. Vingt-sept heures après, les laits de tous les trayons de la vache $n^{\circ} X$ étaient déjà défectueux, mais pas au même degré; on a trouvé le goût le plus fortement huileux-ranci et amer dans le lait du quartier antérieur gauche. De même pour la vache $n^{\circ}$ XI, le défaut des laits des différents quartiers n'était pas également accentué ; le plus fort était le défaut du lait du quartier postérieur gauche.

Au cours de recherehes renouvelées on a encore constaté que les laits des différents quartiers présentaient le défaut étudié, inégalement. Les mélanges des laits des différents quartiers, effectués aussitôt après la traite, prenaient un goût beaucoup plus défectueux que les laits isolés des quartiers particuliers.

Quelle est l'influence de la fermentation lactique sur la formation du défaut ? Pour répondre à cette question, on a ensemencé dans les laits frais, crus, des vaches nos X et XI, des cultures pures des ferments lactiques (Micrococcus lactis), aux doses suivantes : $0,1,0,5$, 1 et $2 \%$. Après l'ensemencement, on a conservé les laits à une température de $16-18^{\circ} \mathrm{C}$. A côté des laits.ensemencés, on a examiné les laits non ensemencés, pour contrôle. Vingt-quatre heures après, les laits non ensemencés avaient un goût huileux-ranci et amer.

Pour les laits ensemencés, on a obtenu le résultat suivant :

Lait $n^{\circ} \mathrm{X}$ avec $0,1 \%$ de la culture : goût huileux-ranci.

Lait $n^{\circ} \mathrm{X}$ avee $0,5 \%$ de la culture : goût peu huileux-ranci.

Lait $\mathrm{n}^{\circ} \mathrm{X}$ avec $1,0 \%$ de la culture : très faiblement aigrelet, faiblement huileux-ranci.

Lait no $\mathrm{X}$ avec $2,0 \%$ de la culture : très peu aigrelet.

Lait no $\mathrm{XI}$ avec $0,1 \%$ de la culture : goût ranci-amer.

Lait $n^{\circ} \mathrm{XI}$ avec $0,5 \%$ de la culture : faiblement ranci-amer.

Lait no XI avec $1,0 \%$ de la culture : très faiblement aigrelet.

Lait no XI avec 2,0\% de la culture : aigrelet.

Après quarante-huit heures, on pouvait noter également dans le lait ayant reçu $2 \%$ de culture, un goût ranci remarquable. La 
fermentation du lait ralentit alors l'apparition du goût défectueux, mais elle ne peut pas l'empêcher.

Au cours des recherches faites, sont apparus des changements dans l'intensité de l'altération. Ainsi, pour la vache no VI, le goût défectueux se montrait toujours plus faiblement vers la fin de février; puis il se montrait de nouveau, mais seulement pour quelque temps, car, vers la fin de mars, le goût du lait cru était encore normal après trois jours de conservation au froid. - Pour la vache $\mathrm{n}^{0} \mathrm{X}$, disparaissait vers la moitié de mars le goût ranci-huileux du lait qui avait un arrière-goût très peu salé ; le 31 mars est survenu l'avortement : expulsion du foetus de huit mois. Le renouvellement de la lactation donna alors un lait de goût normal. - La vache no XI avait un lait au goût défectueux plus haut eité pendant tout le temps des recherches.

Même quand on a, le 8 mai, commencé le régime alimentaire d'été, on pouvait, dans le lait de la vache $n^{\circ} \mathrm{XI}$, trouver, 24 heures après la traite, un goût fortement ranci, huileux et amer. Ce goût défectueux était plus fort dans le lait conservé au froid ( $+3^{\circ} \mathrm{C}$.) que dans celui conservé à la température de $+16^{\circ} \mathrm{C}$. Il est évident que le régime d'hiver n'a, dans ce cas, aucune influence sur ce défaut, étant donné que, encore le 2 juin, après un régime d'été de 4 semaines, le lait de la vache ${ }^{0}$ XI était, 24 heures après la traite, fortement ranci et amer.

\section{RÉSUMÉ}

Le lait au goût huileux-ranci et amer (quelquefois aussi suiffeux) se montre ehez quelques vaches, indépendamment du fourrage. Dans les grands troupeaux, ce ne sont pas les laits de toutes les vaches qui présentent de ce défaut, mais seulement certains d'entre eux. Le goût défectueux ne se montre pas dans le lait de la même vache de façon continue, mais il peut disparaître pour quelque temps et puis reparaître. De plus, son intensité varie. Le défaut étudié ne se montrait pas seulement pendant les mois du régime d'hiver, mais aussi au commencement de l'été, au temps du régime d'été. Dans les cas examinés, la plupart des vaches donnant un lait au goût défectueux étaient à un stade avancé de lactation. On peut en conclure une certaine relation entre le goût huileux-ranci (suiffeux) du lait, la gravidité et la période de lactation avancée chez les vaches. Des conclusions analogues ont été énoncées par KöSTLER et surtout par Csiszír. Au commencement de la nouvelle période de lactation, le défaut ne se montrait plus. Le goût huileux-ranci et quelquefois amer ou suiffeux du lait était dans tous les cas examinés de ce genre, tel que, la pasteurisation effectuée à temps, avant que le défaut ne fut noté, était toujours capable d'en empêcher l'apparition. La con- 
servation à des températures inférieures à $+10^{\circ} \mathrm{C}$., était très favorable à la naissance du défaut. Mais, même les températures plus hautes, environ $+18^{\circ}$ à $+20^{\circ} \mathrm{C}$., ne pouvaient empêcher le défaut, elles diminuaient seulement son intensité. Le contact avec le métal, avec l'étain surtout, quand il était d'une durée assez longue, renforça le goût défectueux. Mais même une exclusion totale d'un contact quelconque du lait avec le métal ne pouvait empêcher la naissance de ce défaut. Le goût défectueux commence par l'altération (dégradation) de la matière grasse, au cours de laquelle naissent des substances " de goût " solubles dans l'eau. L'enzyme lipolytique, qui cause la dégradation rapide de la matière grasse du lait, se trouve dans le plasma du lait. Le goût huileux-ranci, éventuellement aussi suiffeux ou amer, n'était pas, dans les cas examinés, provoqué par les microorganismes et on ne peut imputer sa naissance qu'à l'influence de l'enzyme lipolytique. L'effet de cette dernière sur la matière grasse, et, en conséquence, sur le goût du lait, est proportionnel à sa quantité.

Les différents quartiers mammaires de la même vache produisent un lait aux qualités lipolytiques inégalement fortes.

La fermentation du lait, causée par les ferments lactiques, ralentit la naissance du goût huileux-ranci ou suiffeux et amer . dans le lait, mais elle n'est pas capable de l'empêcher.

\section{BIBLIOGRAPHIE}

[1] V. Staffe. Molkerei Ztg. Hildesheim, 43, 85, 1929.

[2] J. Rudolf. Milchwirtschaftl. Forschungen, 8, Bd., 1928.

[3] K. Diernhofer. Milchwirtsch. Forschungen, 10, Bd., 1930.

[4] G. MAJER. Molkerei Ztg. Hildesh., 45, 1931.

[5] W. WINKLER. Milchwirtsch. Zeitung, 38, 1931.

[6] S. KaNDE. Molkerei Ztg. Hildesh., 45, 1931.

- Congrès Intern, de Laiterie 1931.

-. Milchw. Forschungen, Bd. 13, 1932.

[7] A. WeIch et N. BAuER. Fortschritte d. Landw., 7, 1932.

[8] J. Prokš. Zemedelsky archiv, XXII, 1931.

[9] L. S.(PALMER. Journal of Dairy Science, 1922.

[10] J. Gerberet J. Hänı. Schweiz. Zentralbl. f. Milchw., 16, 1927.

[11] G. Köstler, C. L. Roadhouse et W. Lörtscher. Schweiz. Milehzeitung. 1928.

[12] J. Csrszar. Milchwirtsch. Forschungen, 14, Bd., 1932. 